\title{
Functional responses can unify invasion ecology
}

\author{
Jaimie T. A. Dick - Mhairi E. Alexander • Anthony Ricciardi - Ciaran Laverty $\cdot$ Paul O. Downey \\ Meng Xu • Jonathan M. Jeschke • Wolf-Christian Saul • Matthew P. Hill • Ryan Wasserman • \\ Daniel Barrios-O'Neill · Olaf L. F. Weyl · Richard H. Shaw
}

Received: 21 July 2016/Accepted: 19 December 2016/Published online: 18 January 2017

(C) The Author(s) 2017. This article is published with open access at Springerlink.com

\begin{abstract}
We contend that invasion ecology requires a universal, measurable trait of species and their interactions with resources that predicts key elements of invasibility and ecological impact; here, we advocate that functional responses can help achieve this across taxonomic and trophic groups, among habitats and contexts, and can hence help unify disparate research interests in invasion ecology.
\end{abstract}

J. T. A. Dick $(\bowtie) \cdot$ C. Laverty · D. Barrios-O’Neill Institute for Global Food Security, School of Biological Sciences, Queen's University Belfast, Belfast BT9 7BL, Northern Ireland, UK

e-mail: j.dick@qub.ac.uk

C. Laverty

e-mail: claverty14@qub.ac.uk

D. Barrios-O’Neill

e-mail: danny_of_neill@yahoo.co.uk

M. E. Alexander

School of Science and Sport, University of the West of Scotland, Paisley, UK

e-mail: Mhairi.Alexander@uws.ac.uk

\author{
A. Ricciardi \\ Redpath Museum, McGill University, Montreal, \\ QC H3A 0C4, Canada \\ e-mail: tony.ricciardi@mcgill.ca
}

P. O. Downey

Institute for Applied Ecology, University of Canberra,

Bruce, ACT 2601, Australia

e-mail: Paul.Downey@canberra.edu.au
Keywords Functional responses - Resource use Impact prediction · Predator-prey · Invasion hypotheses · Species-traits · Biological control · Context-dependency $\cdot$ Risk assessment

Invasion ecology is fragmented and lacks truly unifying principles across taxonomic and trophic groups, with many widely cited invasion hypotheses

M. Xu

Pearl River Fisheries Research Institute, Chinese Academy of Fishery Sciences/Key Laboratory of Tropical and Subtropical Fishery Resource Application and Cultivation, Ministry of Agriculture, Guangzhou 510380, China

e-mail: xm0557@126.com

J. M. Jeschke - W.-C. Saul

Leibniz-Institute of Freshwater Ecology and Inland Fisheries (IGB), Müggelseedamm 310, 12587 Berlin, Germany e-mail: jonathan.jeschke@gmx.net

W.-C. Saul e-mail: saul@igb-berlin.de

J. M. Jeschke - W.-C. Saul Department of Biology, Chemistry, Pharmacy, Institute of Biology, Freie Universität Berlin, Königin-Luise-Str. 1-3, 14195 Berlin, Germany 
biased towards plants or animals in their development and testing (Catford et al. 2009; Jeschke et al. 2012). Further dis-unity is evidenced with respect to habitats; for example, freshwater and marine invasions conferences consistently fail to amalgamate (e.g. ICAIS versus Marine Bioinvasions) and responsibility for introduced species is often delegated according to a freshwater/marine/terrestrial divide (e.g. in France). Propagule pressure has been suggested as a unifying concept to understand general patterns of invasion success and impact (Ricciardi et al. 2011), but lacks predictive power to explain much of the contextdependent variation that currently impedes risk assessments of invader ecological impacts. Also, whilst the invasion history of a species can help predict its impacts in new locations (Kulhanek et al. 2011; Kumschick et al. 2015), this is of no use for emerging or potential invaders, and again suffers from myriad context-dependencies (Ricciardi et al. 2013). Further, whilst explored extensively, no single species trait, or combination of traits, has thus far provided excellent explanatory or predictive power with respect to the invasiveness and ecological impacts of introduced species (Ricciardi et al. 2013; Dick et al. 2014).

This lack of unity is also manifested in disparity in the language, definitions, concepts and statistical approaches used by invasion ecologists. In particular,

J. M. Jeschke - W.-C. Saul

Berlin-Brandenburg Institute of Advanced Biodiversity

Research (BBIB), Altensteinstr. 34, 14195 Berlin,

Germany

\section{P. Hill}

Centre for Invasion Biology, Stellenbosch University, Private Bag X1, Matieland 7602, South Africa

e-mail: matthill@protonmail.com

R. Wasserman · O. L. F. Weyl

South African Institute for Aquatic Biodiversity (SAIAB),

P. Bag 1015, Grahamstown 6140, South Africa

e-mail: ryanwas21@gmail.com

O. L. F. Weyl

e-mail: O.Weyl@saiab.ac.za

R. Wasserman · O. L. F. Weyl

Centre for Invasion Biology, South African Institute for Aquatic Biodiversity (SAIAB),

P. Bag 1015, Grahamstown 6140, South Africa

R. H. Shaw

CABI UK, Bakeham Lane, Egham TW20 9TY, UK e-mail: r.shaw@cabi.org animal ecologists use the "functional response" concept (resource use in relation to resource availability) with analyses based on Holling's disc and Rogers' random predator equations (e.g. Alexander et al. 2014), whereas plant ecologists generally use Michaelis-Menten kinetics and talk of resource "uptake curves" (e.g. Rossiter-Rachor et al. 2009), "resource use efficiency" (RUE; Funk and Vitousek 2007) and "nutrient responses" (e.g. King and Wilson 2006). In addition, the Fluctuating Resource Availability hypothesis of plant community invasibility (Davis et al. 2000) has parallels with functional responses, as both relate resource uptake to resource supply in determining invasion risk. Further, whilst animal ecologists use functional responses in terms of impact on resource populations (usually prey), the "functional resource utilization response" as used by Tilman et al. (1977) explicitly brings resource use rates, at least in plants, into the realms of interspecific competition (see also below). Both plant and animal invasion ecologists are therefore working on the same principle, that of resource uptake and its predictive capacity for many aspects of invasions. Indeed, resource uptake rate-whether predator/prey, herbivore/plant, plant/nutrient, or in fact any organism/ resource interaction-is truly fundamental to all species (see also Real 1977). We thus propose that functional responses (and their namesake variants) have the potential to unify invasion ecology across taxa, trophic levels and habitats as a measurable species trait and resource interaction with significant predictive capacity. This could clearly extend to the majority of hypotheses in invasion ecology, as resource use is a central mechanism in 28 of 29 hypotheses listed by Catford et al. (2009) to explain invasion success, and resource use also features in several hypotheses listed by Ricciardi et al. (2013) to explain spatio-temporal variation in ecological impact.

Comparative functional responses, whereby the relationship between resource availability and resource uptake rate is derived and compared among species (Dick et al. 2014), have thus far consistently revealed that high ecological impact invaders have higher maximum feeding/consumption rates than trophically analogous natives-whether animal (predator or herbivore), plant, vertebrate or invertebrate, aquatic or terrestrial (Fig. 1). This is also often accompanied by higher attack rates (classically curve 
(a)

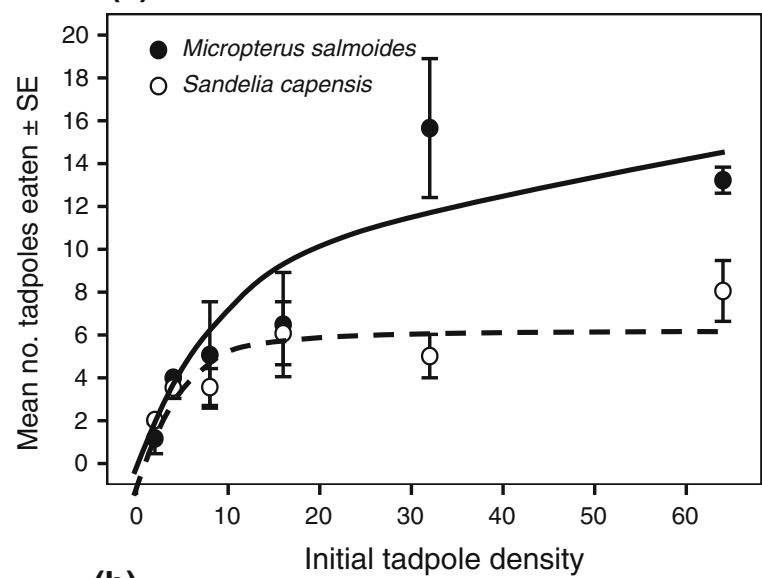

(b)
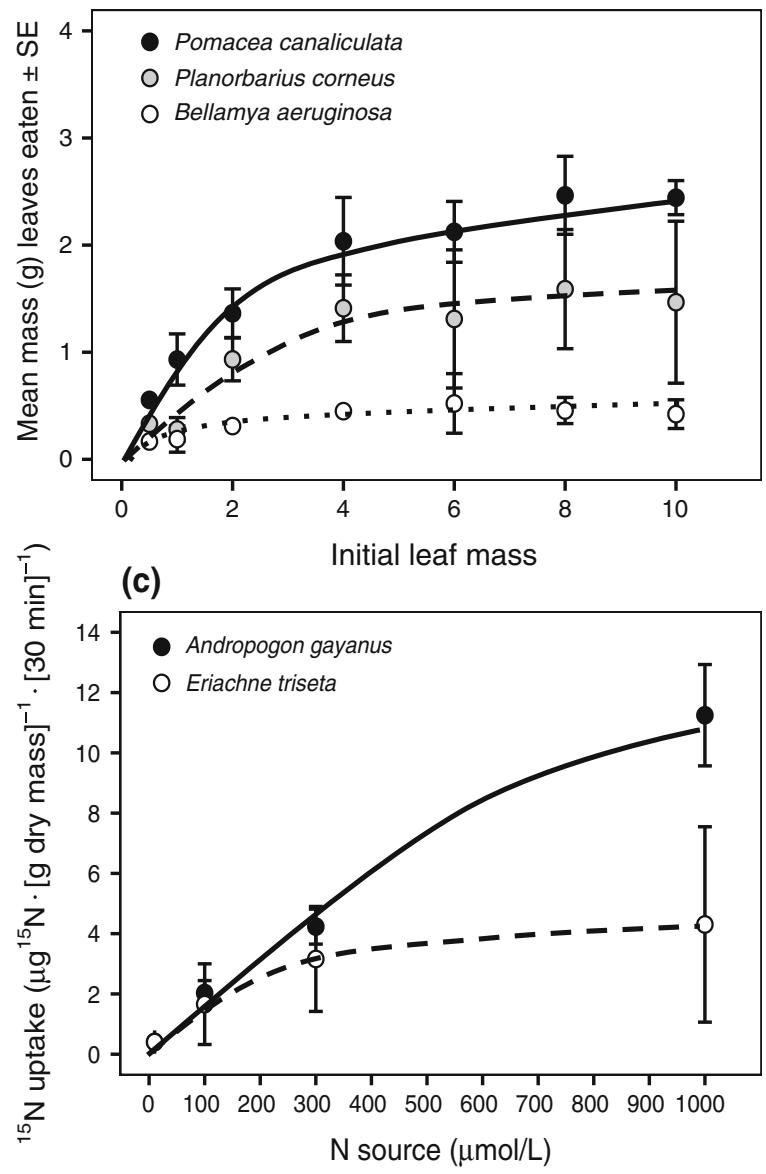

Fig. 1 Functional responses of ecologically damaging invaders have higher asymptotes compared to those of native analogues, across taxa, trophic groups and habitats: invasive/native comparisons are a Largemouth bass/Cape Kurper; b Golden apple snail/Chinese snail (middle curve is emerging invader, the greater ramshorn snail); c gamba grass/Australian grass; d- (d)

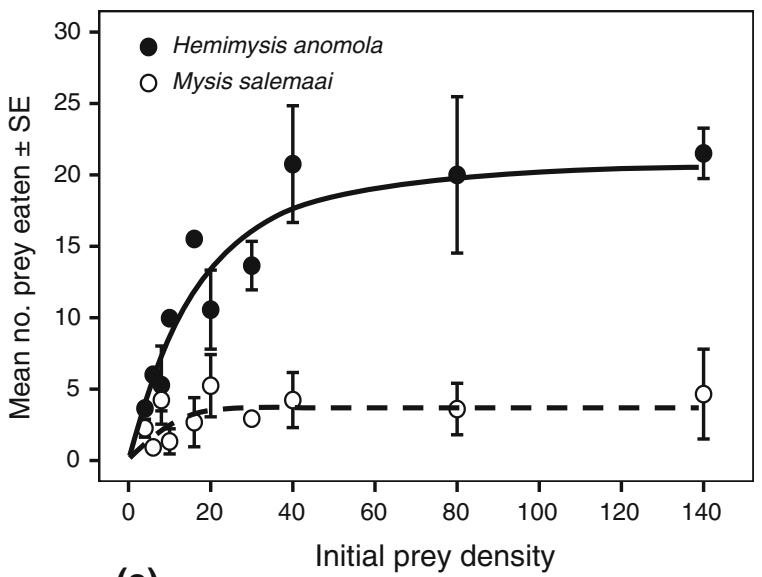

(e)

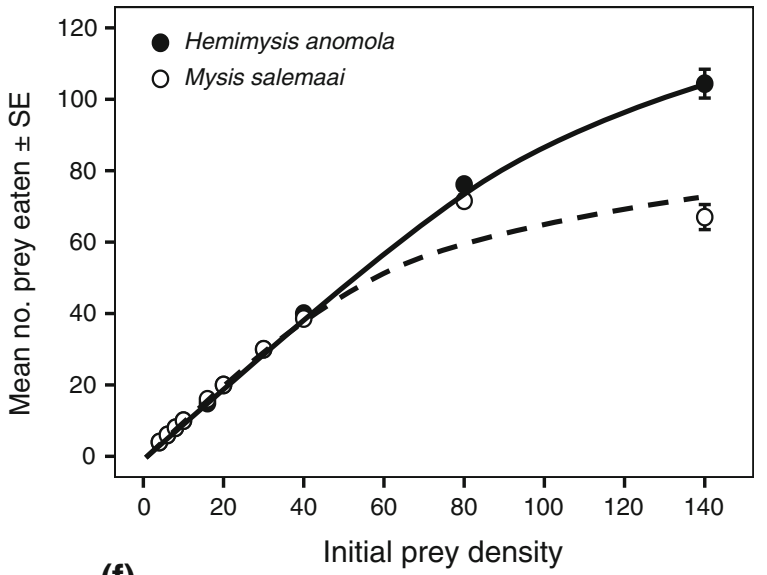

(f)

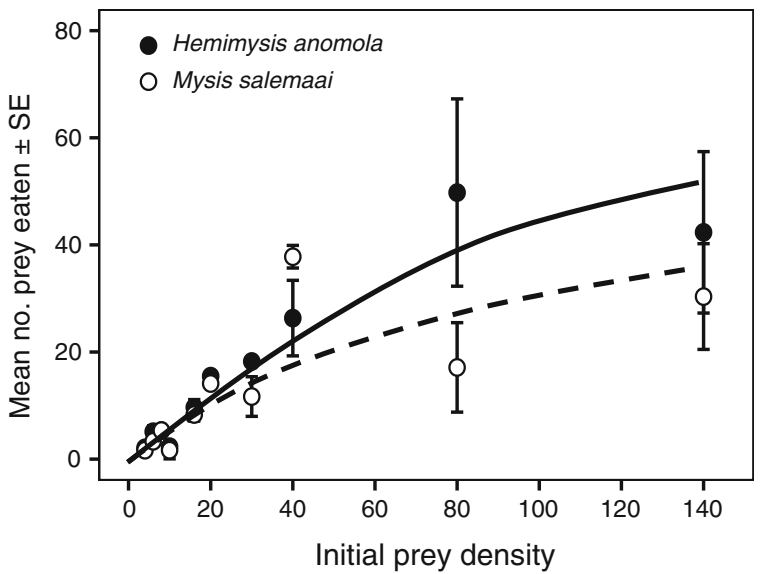

f bloody red shrimp/opossum shrimp. In this latter example, the degree of difference in invader/native functional responses correlates with degree of actual field impact of invader on cladocerans (high impact; d, e) and copepods (low impact; f). Redrawn from Alexander et al. (2014), Xu et al. (2016), Rossiter-Rachor et al. (2009) and Dick et al. (2013) 
parameter "a") and differences in curve shape, generally variants of Type II and III functional responses, which have implications for resource population stability (see Dick et al. 2014). We therefore propose that functional responses, and their equivalents in terms of, for example, nutrient uptake curves, are inherently measurable species traits of invaders and natives, and their interactions with resources, that can truly unify the drive to increase explanatory and predictive power in invasion ecology. For example, while most invader/native functional response comparisons to date have examined predator-prey systems (e.g. Dick et al. 2013), there are emerging studies involving herbivore-plant (Xu et al. 2016) and plant-nutrient interactions (see RossiterRachor et al. 2009). The latter study, by using completely different terminologies, led to the existence of essentially similar thinking by animal and plant invasion scientists - who, thus far, have had little collaborative interaction or consideration of each other's research.

Functional responses can be viewed partially as inherent characteristics of species with the strength and shape of interactions modified by the various resources in question and extrinsic context-dependencies. Although abiotic and biotic context-dependencies have been a major challenge to ecological impact prediction in invasion ecology (Ricciardi et al. 2013; Kumschick et al. 2015), we contend that functional responses can go a long way to mitigate this problem. By explicitly incorporating relevant context-dependencies into functional response study designs and hypothesis testing, both explanatory and predictive power are enhanced (Dick et al. 2010; Paterson et al. 2015; Barrios-O'Neill et al. 2016); for example, functional responses of invasive meso-predators may be affected by the presence of higher predators (Barrios-O'Neill et al. 2014) and impact predictions from such studies can be made even with regards to the complex world of real communities. Similarly, consideration of changes or differences in the physical environment, such as habitat complexity and water chemistry, can allow impact prediction, owing to shifts in the shape and magnitude of functional responses under such context-dependencies (e.g. Alexander et al. 2015; Iacarella and Ricciardi 2015; Laverty et al. 2015). Whilst not all potential contexts and their interactions can be captured in such studies, those identified as the most relevant can be, and this approach has facilitated the development of general ecological impact models with functional responses at their core (e.g. Iacarella et al. 2015).

We have encountered a number of confusions, misunderstandings and questions with respect to what comparative functional responses can actually do for invasion ecology. For example, we do not explicitly relate functional responses to resource competition between the invader and native trophic comparator. This is because displacement of a native by an invader may be driven by interactions other than competition; for example, while the invasive amphipod Gammarus pulex has higher functional responses towards shared prey than the native $G$. duebeni celticus which is displaced (Laverty et al. 2015), it is intraguild predation rather than competition that drives this replacement process (Dick 2008). The higher functional responses of the invader correlates with its impact on the broader ecological community, which might invoke interspecific competition, but this is not explicit in the functional response studies to date. Nevertheless, we foresee incorporation of functional responses into competition theory and experimentation, since resource consumption is central to both concepts. Indeed, there is some dis-unity with respect to animal and plant studies of competition, evident when considering that Tilman (1977), for example, explicitly utilised resource uptake rates in plant competition studies, yet this use of functional responses is missing from animal competition studies. Further, incorporating the results from functional response experiments into models of the functional niche (Leibold 1995) of a potential invader might allow for a more mechanistic prediction of the likely impacts of such species.

In addition, while comparative functional responses may be directly related to impacts on the resources in question (e.g. prey species impacted in a predatorprey system), the impacts of the invader may be diverse and not only on the resource itself; for example, invasive gamba grass (Androbogon gayanus) impacts communities through changes in fire regimes, but its identification as a successful invader with high-impact could still be predicted by its higher functional response (see Fig. 1c). This raises the further issue as to what stages of invasion (see Blackburn et al. 2011) could be better understood by functional response studies. We suggest that functional responses could shed light on which species 
(with feeding stages) can survive transportation (e.g. in ballast water tanks) and become established in new locations-where resources might be in short supply or already being utilised by existing native species. Similarly, invader establishment and spread may be facilitated by resource use patterns, again measurable by functional response studies, and species invasiveness as distinct from ecological impact (see Ricciardi and Cohen 2007) may also be correlated with functional responses (see Bovy et al. 2015; Xu et al. 2016). One aspect that might considerably improve the use of functional responses in such contexts would be incorporation of abundance, as per Parker et al. (1999), which is essentially the numerical response that, together with the functional response, gives the total response (or total uptake rate; see Dick et al. 2014). Finally, studies relating functional responses to actual field impacts show great promise in explanatory and predictive power (Dick et al. 2013) and thus we believe that they will guide further development of invasion theory, such as the mechanistic bases for ecological impact, and the roles of prey naiveté, ecoevolutionary experience and history in invasion ecology (Saul and Jeschke 2015).

Risk assessment of invasion threats would naturally consider probabilities and degrees of establishment and impact, both of which could be elucidated by functional responses (Dick et al. 2013, 2014). We advocate that current and emerging invaders of concern, such as those identified by national and international regulatory agencies (e.g. new EU Regulation 1143/2014) be tested for functional responses in a standardized way, analogous to tests of target specificity and efficacy of biological control agents (see Fernández-Arhex and Corley 2003; Finlay-Doney and Walter 2012). Indeed, the biological control community has essentially been asking the same question as invasion ecologists for many decades (and indeed using functional and numerical responses) of what are technically beneficial introduced species based on their predicted impact when released into the environment.

With facilities already existing around the world, such as individual university research laboratories and dedicated biological control research facilities (e.g. $\mathrm{CABI}$ ), the routine functional response testing of introduced species (current, emerging and potential future), across all taxa, trophic groups and habitats, is surely feasible. This has the potential to not only unite invasion ecology, but provide a truly predictive science with greater real-world applicability.

Acknowledgements This paper is the result of a workshop hosted and part-funded by the Centre for Invasion Biology, University of Stellenbosch, South Africa, November 2015. JMJ and WCS additionally acknowledge support from the Deutsche Forschungsgemeinschaft (DFG; JE 288/7-1, JE 288/9-1) and the ERA-Net BiodivERsA (project FFII). RJW acknowledges funding from the National Research Foundation of South Africa. MX acknowledges funding from the National Natural Science Foundation of China (31400487). Emmanuelle Sarat is our French connection.

Open Access This article is distributed under the terms of the Creative Commons Attribution 4.0 International License (http:// creativecommons.org/licenses/by/4.0/), which permits unrestricted use, distribution, and reproduction in any medium, provided you give appropriate credit to the original author(s) and the source, provide a link to the Creative Commons license, and indicate if changes were made.

\section{References}

Alexander ME, Dick JTA, Weyl OLF, Robinson TB, Richardson DM (2014) Existing and emerging high impact invasive species are characterized by higher functional responses than natives. Biol Lett 10:20130946. doi:10. 1098/rsbl.2013.0946

Alexander ME, Kaiser H, Weyl OLF, Dick JTA (2015) Habitat simplification increases the impact of a freshwater invasive fish. Environ Biol Fish 98:477-486

Barrios-O'Neill D, Dick JTA, Emmerson MC, Ricciardi A, MacIsaac HJ, Alexander ME, Bovy HC (2014) Fortune favours the bold: a higher predator reduces the impact of a native but not an invasive intermediate predator. J Anim Ecol 83:693-701

Barrios-O'Neill D, Ruth K, Dick JTA, Ricciardi A, MacIsaac H, Emmerson M (2016) On the context-dependent scaling of consumer feeding rates. Ecol Lett 19:668-678. doi:10. 1111/ele.12605

Blackburn TM, Pysek P, Bacher S, Carlton JT, Duncan RP, Jarosik V, Wilson JRU, Richardson DM (2011) A proposed unified framework for biological invasions. Trends Ecol Environ 26:333-339

Bovy HC, Barrios-O'Neill D, Emmerson MC, Aldridge DC, Dick JTA (2015) Predicting the predatory impacts of the "demon shrimp" Dikerogammarus haemobaphes, on native and previously introduced species. Biol Invasions 17:597-607

Catford JA, Jansson R, Nilsson C (2009) Reducing redundancy in invasion ecology by integrating hypotheses into a single theoretical framework. Divers Distrib 15:22-40

Davis MA, Grime JP, Thompson K (2000) Fluctuating resources in plant communities: a general theory of invasibility. J Ecol 88:528-534

Dick JTA (2008) Role of behaviour in biological invasions and species distributions; lessons from interactions between the 
invasive Gammarus pulex and the native G. duebeni (Crustacea: Amphipoda). Contrib Zool 77:91-98

Dick JTA, Armstrong M, Clarke HC, Farnsworth KD, Hatcher MJ, Ennis M, Kelly A, Dunn AM (2010) Parasitism may enhance rather than reduce the predatory impact of an invader. Biol Lett 6:636-638

Dick JTA, Gallagher K, Avlijas S, Clarke HC, Lewis SE, Leung S, Minchin D, Caffrey J, Alexander ME, Maguire C, Harrod C, Reid N, Haddaway NR, Farnsworth KD, Penk M, Ricciardi A (2013) Ecological impacts of an invasive predator explained and predicted by comparative functional responses. Biol Invasions 15:837-846

Dick JTA, Alexander ME, Jeschke J, Ricciardi A, MacIsaac H, Robinson T, Kumschick S, Weyl OLF, Dunn AM, Hatcher MJ, Paterson RA, Farnsworth KD, Richardson DM (2014) Advancing impact prediction and hypothesis testing using a comparative functional response approach. Biol Invasions 16:735-753. doi:10.1007/s10530-013-0550-8

Fernández-Arhex V, Corley JC (2003) The functional response of parasitoids and its implications for biological control. Biocon Sci Technol 13:403-413

Finlay-Doney M, Walter GH (2012) The conceptual and practical implications of interpreting diet breadth mechanistically in generalist predatory insects. Biol J Linn Soc 107:737-763

Funk JL, Vitousek PM (2007) Resource-use efficiency and plant invasion in low resource systems. Nature 446:1079-1081

Iacarella JC, Ricciardi A (2015) Dissolved ions mediate body mass gain and predatory response of an invasive fish. Biol Invasions 17:3237-3246

Iacarella JC, Dick JTA, Alexander ME, Ricciardi A (2015) Ecological impacts of invasive alien species along temperature gradients: testing the role of environmental matching. Ecol Appl 25:706-716

Jeschke JM, Gómez Aparicio L, Haider S, Heger T, Lortie CJ, Pyšek P, Strayer DL (2012) Support for major hypotheses in invasion biology is uneven and declining. NeoBiota 14:1-20

King WMCG, Wilson JB (2006) Differentiation between native and exotic plant species from a dry grassland: fundamental responses to resource availability, and growth rates. Aust Ecol 31:996-1004

Kulhanek SA, Ricciardi A, Leung B (2011) Is invasion history a useful tool for predicting the impacts of the world's worst aquatic invasive species? Ecol Appl 21:189-202

Kumschick S, Gaertner M, Vilà M, Essl F, Jeschke JM, Pyšek P, Bacher S, Blackburn TM, Dick JTA, Evans T, Hulme PE,
Kühn I, Mrugała A, Pergl J, Rabitsch W, Ricciardi A, Richardson DM, Sendek A, Winter M (2015) Ecological impacts of alien species: quantification, scope, caveats and recommendations. Bioscience 65:55-63

Laverty C, Dick JTA, Alexander ME, Lucy FE (2015) Differential ecological impacts of an invader and a native under environmental change are revealed by comparative functional responses. Biol Invasions 17:1761-1770

Leibold M (1995) The niche concept revisited: mechanistic models and community context. Ecology 76:1371-1382

Parker IM, Simberloff D, Lonsdale WM, Goodell K, Wonham M, Kareiva PM et al (1999) Impact: toward a framework for understanding the ecological effects of invaders. Biol Invasions 1:3-19

Paterson R, Dick JTA, Pritchard D, Ennis M, Hatcher MJ, Dunn AM (2015) Predicting invasive species impacts: a community module functional response approach reveals context dependencies. J Anim Ecol 84:453-463

Real LA (1977) The kinetics of functional response. Am Nat 111:289-300

Ricciardi A, Cohen J (2007) The invasiveness of an introduced species does not predict its impact. Biol Invasions 9:309-315

Ricciardi A, Jones L, Kestrup ÅM, Ward JM (2011) Expanding the propagule pressure concept to understand the impact of biological invasions. In: Richardson DM (ed) Fifty years of invasion ecology: the legacy of Charles Elton. Blackwell, London, pp 225-235

Ricciardi A, Hoopes MF, Marchetti MP, Lockwood JL (2013) Progress toward understanding the ecological impacts of non-native species. Ecol Monogr 83:263-282

Rossiter-Rachor NA, Setterfield SA, Douglas MM, Hutley LB, Cook GD, Schmidt S (2009) Invasive Andropogon gayanus (gamba grass) is an ecosystem transformer of nitrogen relations in Australian savanna. Ecol Appl 19:1546-1560

Saul W-C, Jeschke JM (2015) Eco-evolutionary experience in novel species interactions. Ecol Lett 18:236-245

Tilman D (1977) Resource competition between planktonic algae: an experimental and theoretical approach. Ecology 58:338-348

Xu M, Mu X, Dick JTA, Fang M, Gu D, Luo D, Zhang J, Luo J, $\mathrm{Hu}$ Y (2016) Comparative functional responses predict the invasiveness and ecological impacts of alien herbivorous snails. PLoS One 11:e0147017. doi:10.1371/journal.pone. 0147017 